\title{
Death Ideation in Cancer Patients: Contributing Factors
}

\author{
NUNO MADEIRA, MD \\ Serviço de Psiquiatria - Hospitais da Universidade de Coimbra, Coimbra, Portugal \\ EMÍLIA ALBUQUERQUE, MD \\ Unidade de Psiquiatria —Instituto Português de Oncologia de Coimbra, Coimbra, Portugal \\ TIAGO SANTOS, MD \\ Departamento de Psiquiatria e Saúde Mental—Hospital Infante D. Pedro, Aveiro, Portugal \\ ALEXANDRE MENDES, MD \\ Centro Hospitalar Psiquiátrico de Coimbra, Coimbra, Portugal \\ MARTA ROQUE, MD \\ Departamento de Psiquiatria-Hospital de S. Sebastião, Feira, Portugal
}

\begin{abstract}
Advances in cancer research and therapy have improved prognosis and the quality of life of many patients. However, previous epidemiological studies in oncologic patients have shown an increased risk of suicide. Suicidal thoughts, relatively well known in those terminally ill, may be just as important for cancer patients who are survivors or are living with the disease. Nonetheless, there is a relative paucity of data about suicidality in this setting. The authors conducted a prospective observational study to identify death thoughts and to explore the factors associated with suicidal ideation in cancer patients. A sample of 130 patients referred for psychiatric consultation was obtained following informed consent and authorization from the local ethics committee. A semistructured interview assessed sociodemographic data, psychosocial support, and information regarding the cancer process and its treatment. Psychometric instruments were used to evaluate psychopathology, namely the Hospital Anxiety and Depression Scale, the Beck Hopelessness Scale, and the Beck Scale for Suicide Ideation. Psychiatric diagnoses were obtained through the application of the Mini International Neuropsychiatric Interview. Death ideation was identified in 34.6\% of
\end{abstract}

Address correspondence to Nuno Madeira, MD, Hospitais da Universidade de Coimbra, Serviço de Psiquiatria, Praceta Mota Pinto, Coimbra, 3000-075 Portugal. E-mail: nunomadeira@huc.min-saude.pt 
patients, yet only 10\% had active suicidal thoughts. Risk of suicide was associated with female gender, a psychiatric diagnosis (major depressive disorder, panic disorder, or dysthymia), difficult interpersonal relationships, associated pain, high bopelessness, and depressive and anxiety symptoms. Although suicidal thoughts are frequent in cancer patients at different stages of disease, most are transitory. Risk factors for suicidal ideation have been identified, such as depression, bopelessness, uncontrolled pain, and difficult interpersonal relationships. Further assessment is necessary to identify those at higher risk of attempting suicide, and underlying psychiatric disorders should be vigorously treated.

KEYWORDS suicide, death, cancer

\section{INTRODUCTION}

The desire for death in cancer patients has been the subject of fierce debate not only in the scientific community, but also outside the medical setting (Cohen et al., 2006; Corn, 2009; Gielen, van der Branden, \& Broeckaert, 2008; Quill, 2004). In fact, few issues have raised such controversy in medicine other than euthanasia and assisted suicide.

From a philosophical point of view, many face suicide in an oncological setting, especially in advanced phases of disease, as rational (Karlsson, Milberg, \& Strang, 2011; Rietjens, van Tol, Schermer, \& van der Heide, 2009). Such a desire would prevail as a legitimate form of escape from a painful and relentless disease, through a somehow merciful death. However, from a psychiatric perspective, the desire for death in cancer patients is the key construct of a set of phenomena that includes suicidal ideation-active or passive, a desire for assisted suicide or euthanasia, suicide attempts, and consummated suicide (Brown, Henteleff, Barakat, \& Rowe, 1986). All of them are common in the oncologic setting, where suicidal ideas frequently work as an escape valve, a way of ventilating hard-to-integrate emotions, like the patient who says to the attending physician, "If things get too bad, I'll always have an exit" (Breitbart, 1990), somehow maintaining some grip on a potentially painful and uncontrollable situation. Those are usually transient thoughts verbalized in the context of a trust-based relationship that become persistent only in a depressive state.

Factors of vulnerability to suicide in cancer patients have been identified, such as depression, hopelessness, previous psychiatric morbidity or suicide behavior, family history of suicide, uncontrolled pain, multiple physical symptoms, advanced phase of disease, bad prognosis, delirium, single status, unemployment, isolation, and lack of social support (Ahn et al., 2010; Breitbart, \& Passik, 1995; Robson, Scrutton, Wilkinson, \& MacLeod, 2010). 
To our knowledge, only one study has been done in Portugal regarding this subject, with a relatively small sample and brief evaluation and data analysis (Guete et al., 2003). At a time of particular debate about the management of death ideation in oncology, we proposed to evaluate a comprehensive list of demographic, clinical, and psychometric variables in a larger clinical sample, to pursue a better comprehension of the modelling factors of death ideation in Portuguese cancer patients.

\section{METHOD}

Upon approval from the local Ethics Committee, we evaluated 130 first-time consecutive referrals to the Psychiatric Unit of the Portuguese Institute of Oncology in Coimbra, between April and September 2009. Psychometric assessment was made through the application of the Hospital and Anxiety Depression Scale, Beck Hopelessness Scale, and Beck Suicidal Ideation Scale; the Mini-International Neuropsychiatric Inventory (M.I.N.I.) was used for diagnostic procedures. Sociodemographic data was collected, as well as information regarding the oncologic disease and its treatment.

The Hospital Anxiety and Depression Scale (HADS) is a psychometric instrument for the self-assessment of anxiety and depression in the general hospital setting, useful for patients with relevant medical comorbidity. It is composed of two subscales - anxiety (HADS-A) and depression (HADS-D), having high sensibility and an easy application (Zigmond \& Snaith, 1983). We used the Portuguese version of the HADS (Pais-Ribeiro et al., 2007). The Beck Hopelessness Scale (BHS) is a self-assessment instrument containing 20 questions designed to assess negative attitudes toward the future, recognizing significant hopelessness, which can favor suicidal attempts (Beck \& Steer, 1991; Cunha, 2001). The Beck Suicide Ideation Scale (BSIS) is a psychometric instrument that assesses suicidal thoughts, attitudes, plans, and previous behaviours. Its validity and sensibility are widely documented (Beck, Steer, \& Ranieri, 1988; Cunha, 2001). The M.I.N.I. is a semistructured clinical interview that allows a quick recognition of psychiatric diagnoses according to the Diagnostic and Statistical Manual (DSM-IV) of the American Psychiatric Association (Amorim, 2000; Sheehan et al., 1998).

Several variables presumed to be relevant to the study of death ideation in this setting were assessed, namely sociodemographic (gender, age, marital status, labor activity, academic degree), psychosocial (interpersonal and family relationships), disease-related (type of cancer, time elapsed since diagnosis, knowledge about diagnosis, performance status, existence of significant pain), and psychiatric data (diagnoses obtained from the M.I.N.I. interview and psychometric data from the HADS, BSIS, and BHS). Statistical analysis was made using appropriate software: SPSS (Statistical Package for the Social Sciences, version 17). 


\section{RESULTS}

The individuals studied ( $n=130)$ were mainly of female gender $(73.1 \%)$, married (74.6\%), and middle aged (48\% were between 50 and 64, and 24\% were age 35 to 49 years). Of this sample, $44.6 \%$ lived in the city, whereas a slight majority lived in country areas (55.4\%). Many had primary education (57\%), and most were working (61\%). A vast majority of the patients reported having good interpersonal (96.9\%) and family (92.3\%) relationships.

Regarding disease-related variables, most of the patients had a good functional level (more than 90\% had mild or no symptoms), were going through acute phase treatment (25.2\%), or were in remission $(28.6 \%)$. The most frequent histological types were breast (39\%), digestive (13\%), and ear, nose, and throat ( $9 \%$ ) cancers. Time elapsed since diagnosis frequently exceeded one year (52\%). A vast majority knew the oncologic diagnosis (95.3\%), and more than two thirds considered themselves well informed on their disease. Most of the patients denied severe pain (68\%). Among those who experienced pain, chest and abdomen were the most frequent sites of discomfort. The pain was frequently quite recent ( $<2$ months in 39\% of patients) or long lasting-more than 1 year in 36\% of patients.

The prevalence of psychiatric diagnosis obtained through application of the M.I.N.I. Interview was considerable: only $17 \%$ had no relevant psychopathology. Major depressive episodes (47.7\%), anxiety disorders (generalized anxiety disorder-16.2\%, panic disorder 14.2\%) and adjustment disorders (23.8\%) and dysthymia (10\%) were the most frequent diagnosis.

Although 35\% of the patients experienced suicidal thoughts, defined as a positive "Suicide Risk" item in the M.I.N.I., only 10\% had objective suicidal ideation, assessed through the BSIS.

Patients who had death-related thoughts (Table 1) were more frequently of female gender and reported worst interpersonal relationships or significant physical pain. Higher hopelessness, depression, and anxiety were also associated with death-related thoughts. Other positive correlations were psychiatric comorbidities such a major depressive episode, dysthymia, and panic disorder. A diagnosis of adjustment disorder was significantly less frequent in this group of patients.

Further assessment of the subgroup of patients who had active suicidal thoughts in our sample $(10 \%, n=13)$ revealed statistical significant differences in fewer variables, namely an even higher prevalence of major depression $(76.9 \%, p=.027)$, dysthymia $(30.8 \%, p=.009)$ and most remarkably panic disorder $(46.2 \%, p=.001)$. Psychometric assessment displayed high scores of hopelessness (mean BHS $=12.67, p=.000$ ), depression (mean HADS-D $=12.69, p=.006$ ), and anxiety (mean HADS-A = $12.54, p=.014$ ) in these patients. Other variables displayed no significant differences. 
TABLE 1 Comparison of the Significant Differences Between Groups According to the Presence or Absence of Death-Related Thoughts

\begin{tabular}{lccc}
\hline & $\begin{array}{c}\text { Death Ideation } \\
n=45(35 \%)\end{array}$ & $\begin{array}{c}\text { No Death Ideation } \\
n=85(65 \%)\end{array}$ & $p$ \\
\hline Female gender* & $84.4 \%$ & $67.1 \%$ & 0.034 \\
Bad interpersonal relationships** & $8.9 \%$ & $0 \%$ & 0.005 \\
Presence of pain* & $52.5 \%$ & $25 \%$ & 0.013 \\
Major depressive episode** & $73.3 \%$ & $34.1 \%$ & 0.000 \\
Dysthymia** & $20 \%$ & $4.7 \%$ & 0.005 \\
Panic disorder** & $26.7 \%$ & $8.2 \%$ & 0.004 \\
Adjustment disorder* & $13,3 \%$ & $29,4 \%$ & 0.041 \\
Hopelessness (mean score & 11.33 & 6.17 & 0.000 \\
$\quad$ on BHS)** & 11.87 & 7.19 & 0.000 \\
Depressive symptoms (mean & & & \\
$\quad$ score on HADS-D)** & 11.07 & 9.06 & 0.017 \\
Anxiety symptoms (mean score & & & \\
$\quad$ on HADS-A)* & & & \\
\hline
\end{tabular}

BHS $=$ Beck Hopelessness Scale; HADS-D = Hospital Anxiety and Depression Scale (depression); HADSA $=$ Hospital Anxiety and Depression Scale (anxiety).

${ }^{*} p<0.05,{ }^{* *} p<0.01$.

\section{DISCUSSION}

Prior studies have somehow demonstrated that suicidal nonpersistent thoughts are frequent in cancer patients and long-lasting suicidal ideation, although less common, is still high. In a large cross-sectional survey of cancer patients $(N=2,924), 7.8 \%$ reported thoughts that they would be better off dead or thoughts of hurting themselves (Walker et al., 2008). A study conducted with terminal cancer patients found that $45 \%$ had suicidal nonpersistent thoughts, but only 9\% had long-lasting suicidal ideation (Chochinov et al., 1995). Guete and colleagues (2003), in a previous study in our institution, found a comparable rate of suicidal ideation: $8 \%$ in outpatients.

In this study $35 \%$ of the sample expressed death-related thoughts. As possible modelling factors, we found statistically significant differences in this subgroup suggesting the contribution of the following: (1) psychiatric morbidity: affective disorders such as major depression or dysthymia, but also panic disorder; (2) significant pain; (3) hopelessness; (4) dysfunctional interpersonal relationships; and (5) female gender. Adjustment disorders were less frequent in those with death-related thoughts.

Only $10 \%$ of patients had active suicidal thoughts; such an outcome was associated with an even higher prevalence of major depression, dysthymia, and panic disorder, as well as more significant hopelessness, besides higher depressive and anxiety symptoms. Other variables displayed no significant differences.

This study has several limitations, namely a lack of information on past history of depression and suicidal ideation. Evaluated patients had been referred to psychiatric consultation, which may constitute an important bias. 


\section{Clinical Implications}

Those findings may suggest an association between the severity of suicidal ideation and the intensity of depression, perhaps modulated by hopelessness, panic disorder, and other contributing factors, underlying the need of a careful evaluation of depression and death thoughts in cancer patients. A holistic treatment might therefore include, besides antidepressants with an adequate profile for the oncology patient, psychotherapeutic interventions with proven efficacy in depression (Temple, \& Geddes, 2008; Van Straten, Geraedts, Verdonck-de Leeuw, Andersson, \& Cuijpers, 2010). Our finding of an association of death ideation with depression and dysfunctional interpersonal relationships might favor the consideration of interpersonal therapy (Klerman, Weissman, Rousaville, \& Chevron, 1984). Further investigation of the underlying factors and circumstances of the spectrum of death and suicidal ideation in cancer patients will allow a better approach of these phenomena.

\section{REFERENCES}

Ahn, E., Shin, D. W., Cho, S. I., Park, S., Won, Y. J., \& Yun, Y. H. (2010). Suicide rates and risk factors among Korean cancer patients, 1993-2005. Cancer Epidemiology, Biomarkers \& Prevention, 19(8), 2097-2105.

Amorim, P. (2000). Mini International Neuropsychiatric Interview (MINI): Validação de entrevista breve para diagnóstico de transtornos mentais [Mini International Neuropsychiatric Interview (MINI): Validation of a short structured diagnostic psychiatric interview]. Revissta Brasileira de Psiquiatria, 22(3), 106-115.

Beck, A., \& Steer, R. (1991). Manual for the Beck Scale for Suicide Ideation. San Antonio, TX: Psychological Corporation.

Beck, A., Steer, R., \& Ranieri, W. (1988). Scale for Suicide Ideation: Psychometric properties of a self-report version. Journal of Clinical Psychology, 44(4), 499-505.

Breitbart, W. (1990). Cancer pain and suicide. Advances in Pain Research and Therapy, 16, 399-411.

Breitbart, W., \& Passik, S. (1995). Psychiatric aspects of palliative care. In D. Doyle, G. W. C. Anks, \& N. Macdonald (Eds.), Oxford textbook of palliative medicine (pp. 609-626). Oxford, UK: Oxford University Press.

Brown, J., Henteleff, P., Barakat, S., \& Rowe, C. J. (1986). Is it normal for terminally ill patients to desire death? American Journal of Psychiatry, 143, 208-211.

Chochinov, H. M., Wilson, K. G., Enns, M., Mowchun, N., Lander, S., Levitt. M., \& Clinch, J. J. (1995). Desire for death in terminally ill. American Journal of Psychiatry, 152, 1185-1191.

Cohen, J., Marcoux, I., Bilsen, J., Deboosere, P., van der Wal, G., \& Deliens, L. (2006). Trends in acceptance of euthanasia among the general public in 12 European countries (1981-1999). European Journal of Public Health, 16, 663-669.

Corn, B. W. (2009). Ending end-of-life phobia - A prescription for enlightened health care reform. New England Journal of Medicine, 361(27), e63. Retrieved from http://www.ncbi.nlm.nih.gov/pubmed/20018960 
Cunha, J. (2001). Manual da versão em português das Escalas de Beck [Manual for the Portuguese versions of the Beck Scales]. São Paulo, Brazil: Casa do Psicólogo.

Gielen, J., van den Branden, S., \& Broeckaert, B. (2008). Attitudes of European physicians toward euthanasia and physician-assisted suicide: A review of the recent literature. Journal of Palliative Care, 24, 173-184.

Guete, O., Albuquerque, E., Veiga, F., Santos, Z., Vicente, C., \& Saraiva, C. (2003). Depression, suicidal ideation and hopelessness in cancer patients. Poster presentation at the XXII IASP World Congress, September 10, Stockholm, Sweden.

Karlsson, M., Milberg, A., \& Strang, P. (2011, May 14). Suffering and euthanasia: A qualitative study of dying cancer patients' perspectives. Support Care Cancer. doi:10.1007/s00520-011-1186-9. Retrieved from http://www.ncbi.nlm.nih.gov/pubmed/21573739

Klerman, G., Weissman, M., Rousaville, B., \& Chevron, E. (1984). Interpersonal therapy of depression. New York, NY: Basic Books.

Pais-Ribeiro, J., Silva, I., Ferreira, T., Martins, A., Meneses, R., \& Baltar, M. (2007). Validation study of a Portuguese version of the Hospital Anxiety and Depression Scale. Psychology, Health \& Medicine, 12(2), 225-237.

Quill, T. E. (2004). Dying and decision making-evolution of end-of-life options. New England Journal of Medicine, 350, 2029-2032.

Rietjens, J. A., van Tol, D. G., Schermer, M., \& van der Heide, A. (2009). Judgement of suffering in the case of a euthanasia request in The Netherlands. Journal of Medical Ethics, 35(8), 502-507.

Robson, A., Scrutton, F., Wilkinson, L., \& MacLeod, F. (2010). The risk of suicide in cancer patients: a review of the literature. Psycho-Oncology, 19(12), 1250-1258.

Sheehan, D. V., Lecrubier, Y., Sheehan, K. H., Amorim, P., Janavs, J., Weiller, E., ... Dunbar, G. C. (1998). The Mini-International Neuropsychiatric Interview (M.I.N.I). Journal of Clinical Psychiatry, 59(Suppl 20), 22-33.

Temple, S., \& Geddes, J. (2008). Psychotherapy for depression. In P. Tyrer, \& K. Silk (Eds.), Cambridge textbook of effective treatments in psychiatry (pp. 507-515). New York, NY: Cambridge University Press.

Van Straten, A., Geraedts, A., Verdonck-de Leeuw, I., Andersson, G., \& Cuijpers, P. (2010). Psychological treatment of depressive symptoms in patients with medical disorders: a meta-analysis. Journal of Psychosomatic Research, 69(1), 23-32.

Walker, J., Waters, R. A., Murray, G., Swanson, H., Hibberd, C. J., Rush, R. W., ... Sharpe, M. (2008). Better off dead: Suicidal thoughts in cancer patients. Journal of Clinical Oncology, 26(29), 4725-4730.

Zigmund, A., \& Snaith, R. (1983). The Hospital Anxiety and Depression Scale. Acta Psychiatrica Scandinavica, 67(6), 361-370. 